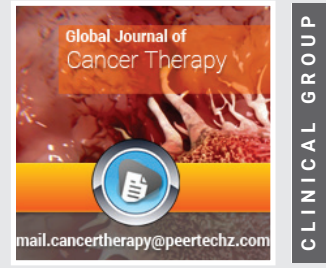

\title{
Efficacy of Neutron
}

\section{Radiotherapy for Primary}

\section{Tracheal Adenoid Cystic}

\section{Carcinoma: A Single Institution Retrospective Analysis}

\author{
Shilpen Patel*, Christine Y Chon, Laura Tedrick, Joshua \\ $K$ Calvert, Dean Lorimer, Justin R Shinn, Jing Zeng and \\ George E Laramore
}

Department of Radiation Oncology, University of Washington, Seattle, Washington 98195-6043, USA

Received: 30 April, 2020

Accepted: 21 May, 2020

Published: 22 May, 2020

*Corresponding author: Shilpen Patel, Department of Radiation Oncology, University of Washington, Seattle, Washington 98195-6043, USA

E-mail: shilpenp@yahoo.com

Keywords: Brachytherapy; Adenoid cystic carcinoma; Neutron radiotherapy

https://www.peertechz.com

\section{Check for updates}

\section{Abstract \\ Background: Primary adenoid cystic carcinoma (ACC) is the second most common primary tracheal neoplasms but the data for optimal treatment plan is limited. This study is an update of our institutional experience treating primary ACC of the trachea with neutron radiotherapy.}

Methods: Between 1993 and 2012, 33 patients with tracheal adenoid cystic carcinoma were treated with curative intent. Two patients received surgery alone, thirteen received adjuvant neutron radiotherapy post surgical resection, and eighteen received neutron radiotherapy as a primary treatment. Median external beam neutron dose was $19.2 \mathrm{~Gy}$.

Two patients who were treated with adjuvant neutron radiotherapy post surgical resection and nine patients treated with neutron radiotherapy alone were also treated with endobronchial brachytherapy boost using high-dose-rate ${ }^{192}$ Ir source (3.5Gy $\times 2$ fractions).

Median duration of follow up was 72.4 months (range $0.9-145.9$ months) post treatment.

Results: Patients who underwent surgery alone, those who received adjuvant neutron radiotherapy post surgical resection, and patients who received neutron radiotherapy as a primary treatment had five-year overall survival rates of $50 \%, 49 \%$ and $93 \%$ ( $p=0.399)$, and five-year disease-free survival rates of $50 \%, 58 \%$ and $38 \%$ $(p=0.702)$ respectively.

The five-year overall survival rates and disease free survival rates for patients who received adjuvant high-dose-rate endobronchial brachytherapy in addition to primary treatment as compared to those who did not were $89 \%$ and $72 \%(p=0.489)$ versus $46 \%$ vs $44 \%(p=0.251)$ respectively.

Conclusions: The data supports the conclusion that adenoid cystic carcinoma of the trachea can be treated with neutron radiation with favorable outcomes.

\section{Introduction}

Primary tracheal neoplasms are rare, occurring in less than 2 persons per 1,000,000 annually and thus very little data is available to guide health care practioners. Adenoid Cystic Carcinoma (ACC) is one of the most common primary tracheal neoplasms, second only to Squamous Cell Carcinoma (SCC)
$[1,2]$. Historically, surgical resection has been the preferred method of curative treatment for ACC of the trachea [3-5]. However, due to the tumor's indolent nature and a low index of clinical suspicion by physicians, patients often present with locally advanced neoplasms which is unresectable at the time of diagnosis. Patients presenting with ACC are sometimes less than ideal surgical candidates and even when they undergo 
surgery, they are occasionally left with an incomplete surgical resection [6-8]. In the setting of inoperable, recurrent or incompletely resected ACC of the head and neck, neutron radiotherapy as primary treatment has been shown to be superior to photon radiotherapy $[9,10]$. Moreover, external beam neutron radiotherapy post-surgical resection has been suggested to improve locoregional control and overall survival $[11,12]$.

Despite advances in treatment, ACC remains a therapeutic challenge due to its slow yet aggressive local behavior and frequent distant spread after long-term, apparent diseasefree intervals. About $30 \%$ of patients eventually develop distant metastases, which have been reported as late as 25 years after diagnosis [13]. For this reason, accumulation of complete patient data requires long follow-up and few centers have accumulated significant patient numbers to report on the management of primary tracheal tumors. The benefits of neutron radiotherapy as a primary or adjuvant treatment remain unclear as do the benefits of HDR endobronchial brachytherapy. More data is needed to achieve better survival and disease-free outcome rates for treated patients $[14,15]$. This report updates our institutional experience treating primary adenoid cystic carcinoma of the trachea with neutron radiotherapy and reports the outcomes of treatment with and without HDR endobronchial brachytherapy.

\section{Materials and methods}

After approval by the Institutional Review Board, patients with adenoid cystic tracheal cancer were identified using the multi-center cancer institution tumor database for all neoplasms of the trachea from 1993 to 2012. Thirty nine patients were identified who had tumors that clearly originated from the trachea and had histologic proof of ACC.

Among the 39 ACC patients, 33 patients were treated with curative intent. Of the 33 patients, 32 received neutron beam radiotherapy as their only form of radiotherapy. One patient was treated with both neutron and photon therapy, receiving 10.7 neutron Gy with 14 photon Gy post surgical resection. Survival analysis of the 33 patients included two patients treated with surgical resection alone, 11 patients who received adjuvant neutron radiotherapy post surgical resection, and 18 patients who received neutron radiotherapy as their primary treatment. Two patients who received initial treatment of surgery and adjuvant neutron radiotherapy and 9 patients, who were treated with neutron radiotherapy alone, without surgery, were additionally treated with endobronchial brachytherapy using HDR ${ }^{192}$ Ir source (Table 1).

Charts were reviewed for demographic features, tumor histology, tumor staging at diagnosis, treatments used and patient outcomes (Table 2). The staging system suggested by Bhattacharyya et al was used as this has been previously used in tracheal malignancies.

\section{Description of treatments}

All patients were treated with a high-energy, Scanditronix (Uppsala, Sweden) MC 50 cyclotron. Fields were individualized
Table 1: Patient Inclusion Criteria (One patient in the Surgery + XRT + HDR received both Neutron and Photon total Gy 24.65).

\begin{tabular}{|c|c|}
\hline Treatment & Number of patients \\
\hline Surgery only & 2 \\
\hline Surgery + XRT & 11 \\
\hline Surgery + XRT + HDR & 2 \\
\hline XRT only & 9 \\
\hline XRT + HDR & 9 \\
\hline
\end{tabular}

Table 2: Univariate survival analysis by Cox Proportional Hazards Patient Population Characteristic Univariate Hazard Ratio

Tobacco use eve

\begin{tabular}{|c|c|c|}
\hline No & 1 (Reference) & - \\
\hline Yes & 2.67 & 0.27 \\
\hline \multicolumn{3}{|l|}{ Gender } \\
\hline Male & 1 (Reference) & - \\
\hline Female & 1.25 & 0.72 \\
\hline \multicolumn{3}{|l|}{ ize of tumor } \\
\hline$\leq 4 \mathrm{~cm}$ & 1 (Reference) & - \\
\hline$>4 \mathrm{~cm}$ & 2.29 & 0.24 \\
\hline \multicolumn{3}{|c|}{ eatment type } \\
\hline NRT only & NRT only & - \\
\hline Surgery only & Surgery only & 0.68 \\
\hline Surg. \& NRT & Surg. \& NRT & 0.37 \\
\hline \multicolumn{2}{|c|}{ Total Rad. Dose } & \\
\hline$<19.2$ & 1 (Reference) & - \\
\hline$\geq 19.2$ & 1.55 & 0.59 \\
\hline \multicolumn{2}{|c|}{ HDR Boost } & \\
\hline Yes & 1 (Reference) & - \\
\hline No & 1.2 & 0.76 \\
\hline
\end{tabular}

according to the location and extent of the primary tumor. A margin of 2 to $3 \mathrm{~cm}$ was used between gross tumor volume and block edge. The median total dose was 19.2 nGy (range,14-28.8 nGy). The most commonly used fractionation schema consisted of 1.2 Gy given 4 times per week to a total dose of 19.2 nGy. Radiobiologic studies suggest an relative biological effectiveness (RBE) of 8 for ACC and 3-3.5 for normal latereacting tissues [16]. As such, a neutron dose of $19.2 \mathrm{~Gy}$ is estimated to be biologically equivalent to a photon dose of 154 Gy to ACC tumor and 67 Gy to normal late-reacting tissues.

To allow for acute tissue recovery, the endobronchial boost was delivered within 1 to 2 months of completing neutron radiotherapy. Endobronchial catheters were placed under general anesthesia, and treatments were delivered with a MicroSelectron 192Ir HDR unit (Nucletron, Veenendaal, The Netherlands). The longitudinal tumor extent was treated to a dose $3.5 \mathrm{~Gy}$, to a median depth of $0.75 \mathrm{~cm}$ (range, $0.5-1 \mathrm{~cm}$ ). A total of two treatments were delivered, for a cumulative dose of 7 Gy. The two treatments were separated by 1 week. 


\section{Patient and tumor characteristics}

The median duration of follow-up for all patients was 72.4 months (range 0.9-145.9 months). There was no statistically significant difference for any of the patient demographics (age, tobacco use, sex) or tumor characteristics taken into account (tumor size, tumor stage, or total radiation dosage) (Table 2).

\section{Statistical analysis}

Data was analyzed using SPSS (version 18.0). An actuarial life-table method was used to calculate the locoregional control rates, disease-free survival rates, and overall survival rates for all patients. These were further classified by treatment

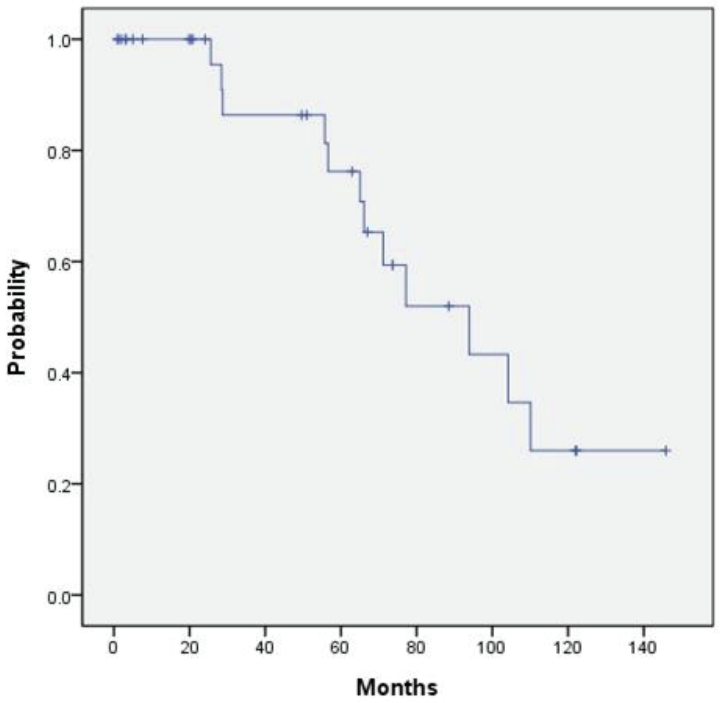

Figure 1a: Overall Survival $(n=33)$

The five-year overall survival for the cohort was $77 \%$, with a median overall survival of 89.5 months.

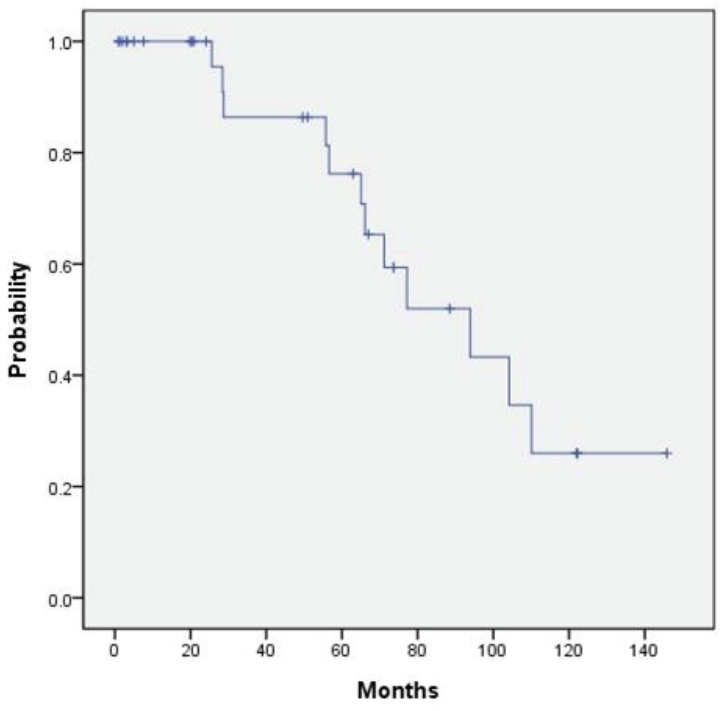

Figure 1b: Disease-free survival $(n=33)$.

The five-year disease-free survival was $44 \%$, with a median disease-free survival of 57.4 months. type, tumor staging, and HDR endobronchial brachytherapy. Corresponding curves were constructed using the KaplanMeier method. Statistically significant differences among the treatment arms were determined using the log-rank test (two-tailed) method. Univariate analysis by Cox Proportional Hazards was determined for age, tobacco use, sex, tumor stage, tumor size, treatment type, total radiation dose and HDR endobronchial brachytherapy. To calculate the overall survival time, date of death for each patient was determined. If death data was not available from patient files or from the social security registries, patients were censored based on the last date seen

\section{Results}

\section{Overall survival, disease-free survival, and locoregional control}

Disease-free and overall survival, the follow-up time was from the date of first treatment to date of recurrence. Patients with unknown recurrence status after their last appointment were censored based on the last date seen.

The five-year actuarial overall survival rate and the median overall survival for the entire cohort were $77 \%$ and 89.5 months. The five-year actuarial disease-free survival rate and the median disease-free survival for the entire cohort were $44 \%$ and 57.4 months. The 5-year overall survival and disease-free survival curves for all patients are $77 \%$ with a median survival of 89.5 months and $44 \%$ with a median disease-free survival of 57.4 months respectively as illustrated in Figures $1 \mathrm{a}$ and $1 \mathrm{~b}$. The overall survival by tumor stage at 5 years as indicated in figure $2(p=0.702)$ shows that tumor stage does not correlate with prognosis: stage $1,100 \%$ alive with median survival of 60 months, stage $2,55 \%$ alive at stage with median survival of 62 months, stage $3,100 \%$ alive with median survival not yet reached and stage $4,75 \%$ alive with median survival of 108 months. We also found that any one treatment type was not associated with a statistically significant increase in overall survival $(p=0.399)$ or disease-free survival $(p=0.702)$ as shown in Figures $3 a$ and $3 b$, respectively. The five year overall survival for surgery alone, surgery and adjuvant radiation and radiation only are $50 \%, 49 \%$ and $93 \%$ respectively. The five year diseasefree survival by surgery alone, surgery and adjuvant radiation and radiation only are $50 \%, 58 \%$ and $38 \%$ respectively.

Overall survival and the disease-free survival for the entire cohort for those who did and did not receive HDR endobronchial brachytherapy is $89 \%$ vs $72 \%(p=0.489)$ and $46 \%$ vs $44 \%$ $(p=0.251)$ as shown in Figures $4 a$ and $4 b$. Adjuvant HDR endobronchial brachytherapy only slightly improved overall survival and disease-free survival when added to the treatment regime. The patients who received neutron radiotherapy as primary treatment with additional HDR endobronchial brachytherapy as compared to those who received neutron radiotherapy alone had an overall survival rate of $88 \%$ and $100 \%$, respectively $(\mathrm{p}=0.659)$ as shown in Figure 5a. Similarly, the disease-free survival for this same cohort was $39 \%$ vs $40 \%$ $(p=0.216)$ as shown in Figure $5 b$. Patients in our cohort treated with adjuvant neutron radiotherapy post surgical resection and

Citation: Patel S, Chon CY, Tedrick L, Calvert JK, Lorimer D, et al. (2020) Efficacy of Neutron Radiotherapy for Primary Tracheal Adenoid Cystic Carcinoma: A Single Institution Retrospective Analysis. Glob J Cancer Ther 6(1): 015-022. DOI: https://dx.doi.org/10.17352/2581-5407.000030 
HDR endobronchial brachytherapy demonstrated improved five-year overall survival and disease-free survival rates compared to those who did not receive HDR endobronchial brachytherapy, although not by a statistically significant factor (Figure $6 \mathrm{a}: 100 \%$ vs. $38 \%$, p=0.484 and Figure $6 \mathrm{~b}: 100 \%$ vs. $47 \%, \mathrm{p}=0.52)$.

The locoregional control curve for all patients is represented in Figure 7a. The 5-year actuarial locoregional control rate for the entire cohort was $72 \%$ and the median survival has not yet

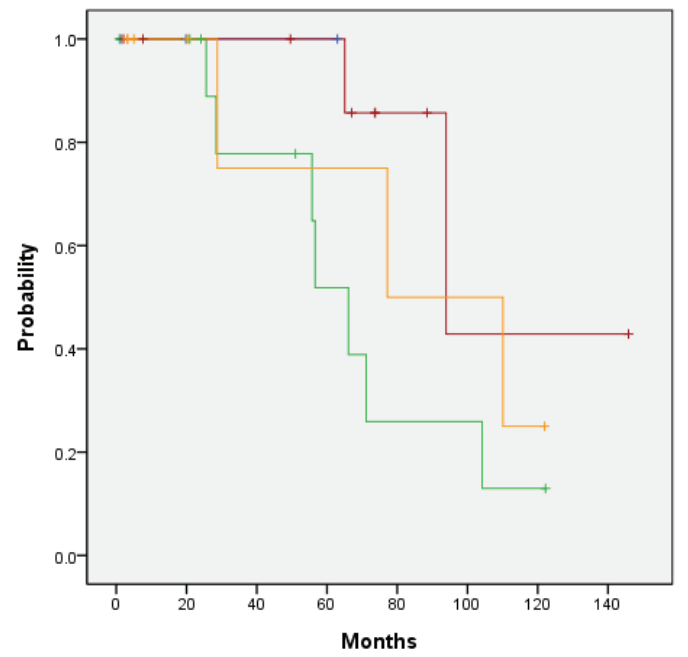

Figure 2: Overall Survival by Tumor stage.

Staging system does not correlate with prognosis.

- Stage 1: $100 \%$ alive at 5 years, median survival 60 months

- Stage 2: $55 \%$ alive at 5 years- median survival time 62.0 months

Stage 3: $100 \%$, median survival time not yet reached

P-Value $=0.124$

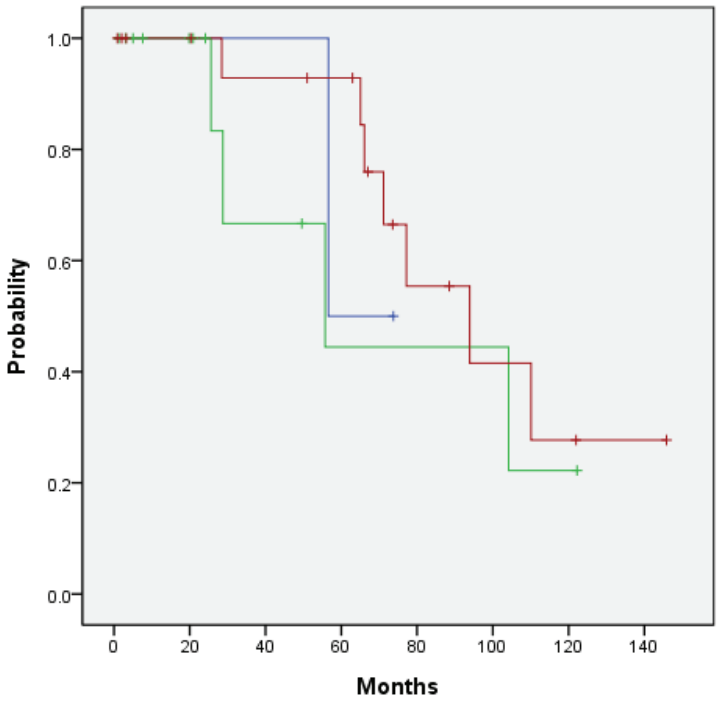

Figure 3a: Overall Survival by Treatment type.

5 year overall survival by tmt type:

- surgery: 50\%, median 72 months

- surgery + NRT $=49 \%$, median 59.7 months

- NRT: $93 \%$, median survival 90.75 months

P-Values $=0.399$ (Wilcoxon non-parametric comparison between 3 groups)

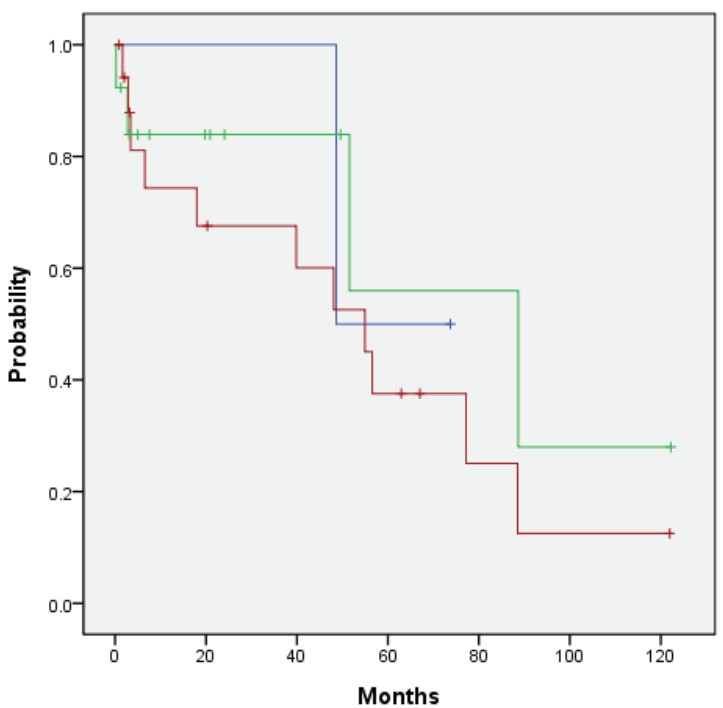

Figure 3b: Disease-free survival by Treatment type.

5 year disease-free survival by tmt type:

- surgery: $50 \%$, median 72.0 months

- surgery + NRT: $58 \%$, median survival 87.5 months

- NRT only: $38 \%$, median survival 53.7 months

P-Value $=0.702$

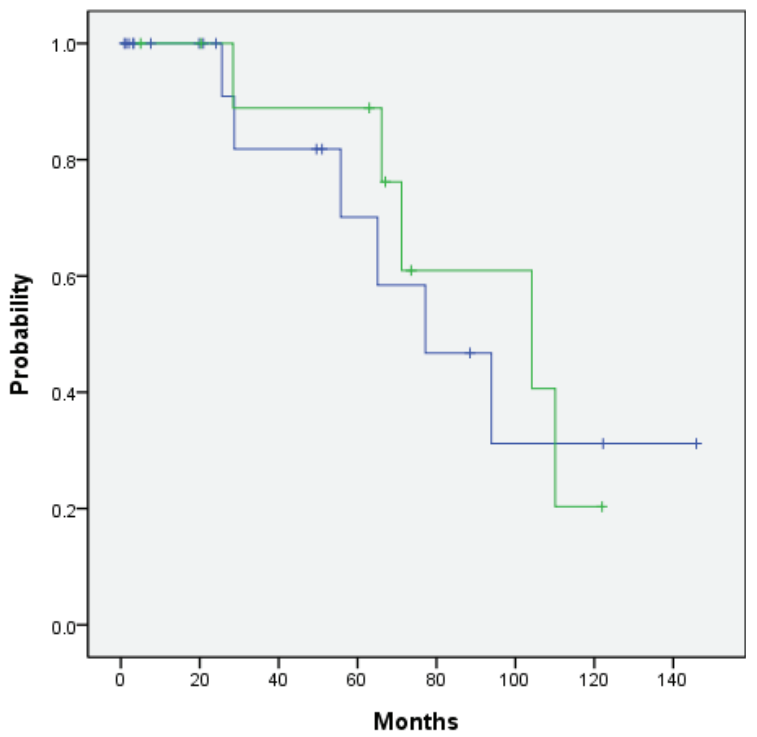

Figure 4a: Overall survival of patient receiving NRT + or - HDR Boost $(n=31)$.

( $n=29$, removed $T x=1$ group)

No HDR, 5 year survival $72 \%$

median survival time $=82.2$ months YES HDR, 5 year survival $89 \%$, median survival time $=103.7$ months $\mathrm{P}$-Value $=0.489$.

been reached. The locoregional control rate among patients receiving neutron radiotherapy alone as compared to those who received adjuvant HDR endobronchial brachytherapy was $87 \%$ vs. $63 \%,(p=0.469)$ as shown in Figure $7 b$.

Univariate analysis was performed to assess the parameters predictive of overall survival in this patient population (Table 1). The parameters examined included age, tobacco use, sex, tumor grade, tumor size, treatment type, dose of radiation and 
HDR endobronchial brachytherapy. In our cohort, increased age, tobacco use, the female sex and a tumor size greater than four centimeters were all associated with increased hazard ratio but were not statistically significant $(\mathrm{p}=0.06,0.27,0.72,0.24$ respectively). Regarding treatment modalities, patients who underwent neutron radiotherapy alone appeared to have lower hazard ratio as compared to patients treated with surgery alone or with neutron radiotherapy adjuvantly post surgical resection ( $\mathrm{p}=0.68$ and $\mathrm{p}=0.37$, respectively). Those who did not receive HDR endobronchial brachytherapy appear to have a somewhat higher hazard ratio, that like the other univariate analyses was not statistically significant $(\mathrm{p}=0.76)$.

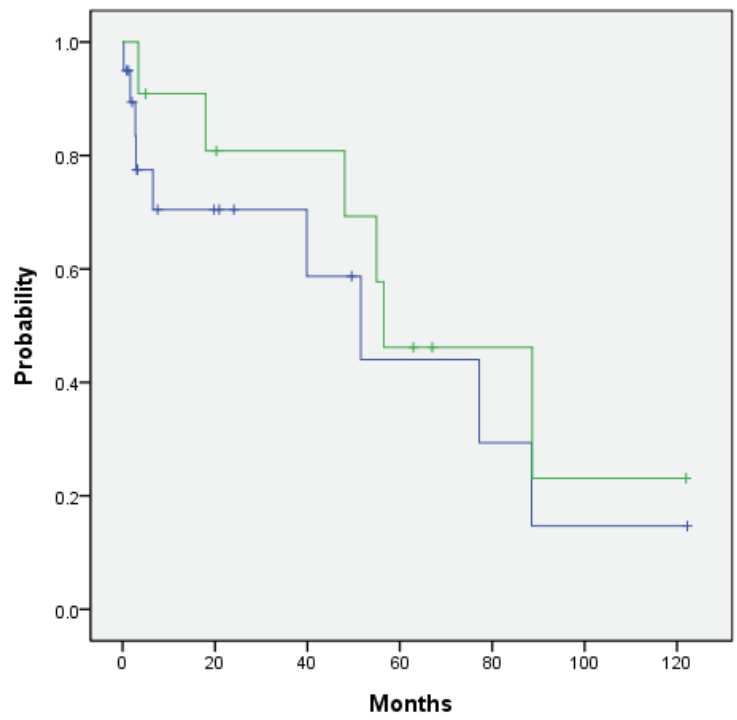

Figure 4b: Disease-free survival of patient receiving NRT + or - HDR Boost $(n=31)$ ( $\mathrm{n}=27$, removed $\mathrm{Tx}=1$ group)

NO HDR, 5 year survival $44 \%$

median survival time $=56.10$ months YES HDR, 5 year survival $46 \%$, median survival time $=58.46$ months $\mathrm{P}$-Value $=0.251$

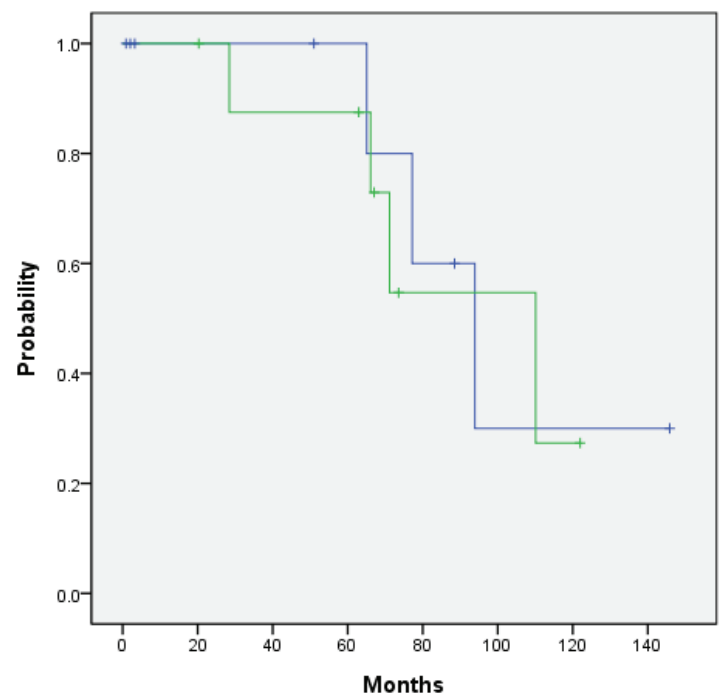

Figure 5a: Overall Survival by HDR $(n=18)$.

NO HDR, 5 year survival $100 \%$,

median survival time $=89.0$ months Yes HDR, 5 year survival $88 \%$, median survival time $=111.4$ months $\mathrm{P}-$ Value $=0.659$

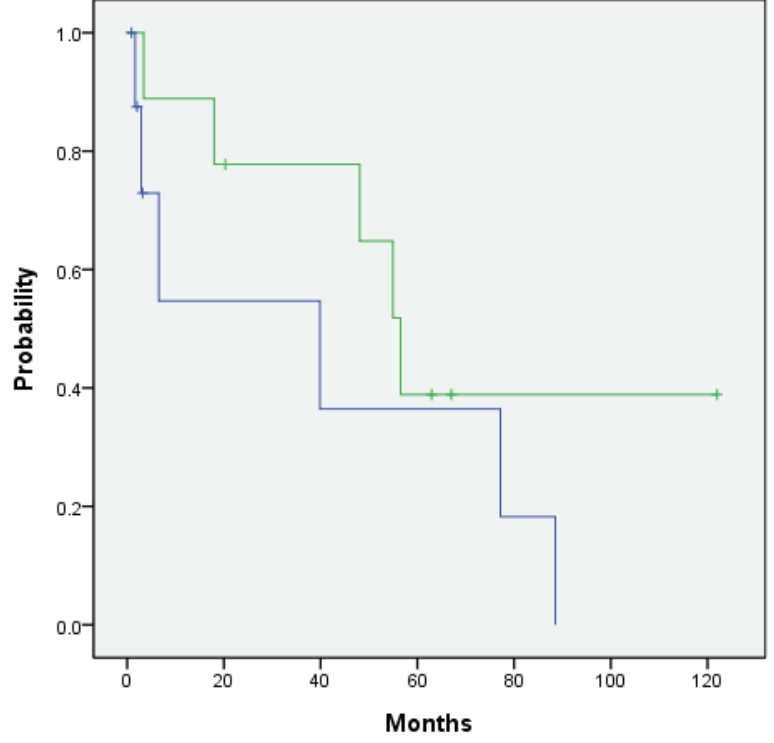

Figure 5b: Disease-free Survival by HDR $(n=18)$

NO HDR, 5 year survival $40 \%$

median survival time $=42.0$ months Yes HDR, 5 year survival $39 \%$,

median survival time $=56.42$ months $\mathrm{P}$-Value $=0.216$

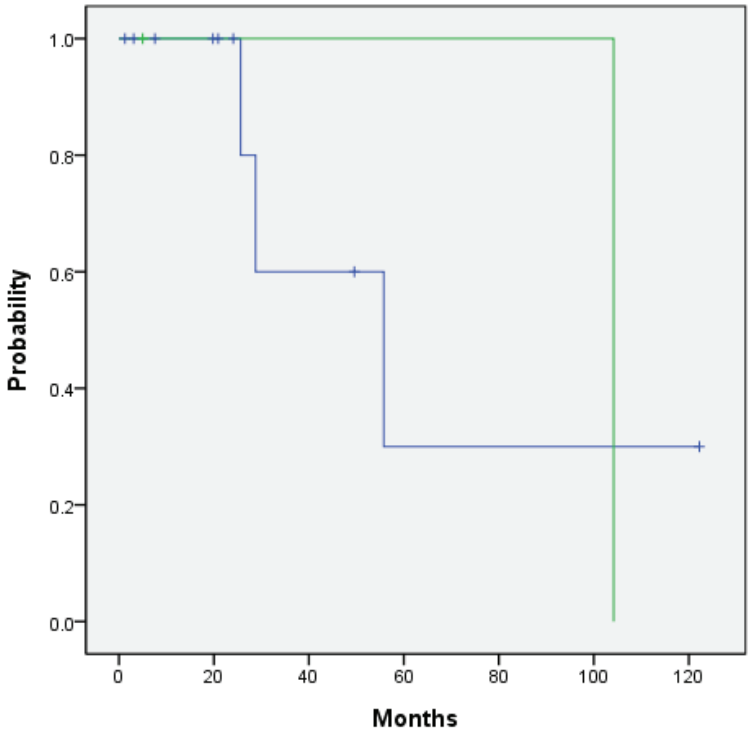

Figure 6a: Overall Survival $(n=13)$

NO HDR Boost $=5$ yr survival $38 \%$,

median survival 54.4 months YES HDR Boost $=5$ yr survival $100 \%$ median survival 102 months $\mathrm{P}$-Value $=0.484$

\section{Patterns of failure and salvage therapy}

Among the 33 patients treated with curative intent, there were 12 documented failures: the site of first failure was local in 6 patients and distant in 6 patients. For those patients who failed locally, the 5-year actuarial survival rate after salvage therapy was $61 \%$ and median survival after salvage therapy was 64.44 months (as shown in Figure 8). The following salvage therapies were used for local failures: tracheal stent placement, laryngotracheoctomy, endobronchial tumor removal, flexible and rigid bronchoscopy with core out and stenting, stereotactic body radiation therapy (SBRT), and chemotherapy with Gleevec. 


\section{Radiation related toxicity}

Among the 33 patients, eight patients incurred radiation related toxicity. The toxicity level was based on the Radiation Therapy Oncology Group (RTOG) Acute Radiation Morbidity Scoring Criteria. Four patients who received neutron radiation only (range of 18.4 to $19.2(\mathrm{~Gy})$ had toxicity grade of 1 to 3. One patient could not safely receive neutron radiation therapy alone and thus received 10.8 neutron Gy and additional 18 photon Gy had a grade 2 toxicity. Three patients who received both neutron radiation and additional endobronchial brachytherapy (range of 17.2 to $18.2 \mathrm{~Gy}$ ) had grade of $1-2$ toxicity. Neither the total radiation dosage nor the addition of HDR endobronchial brachytherapy correlated with the grade of toxicity. There was no increase in the severity of toxicity with the addition of HDR

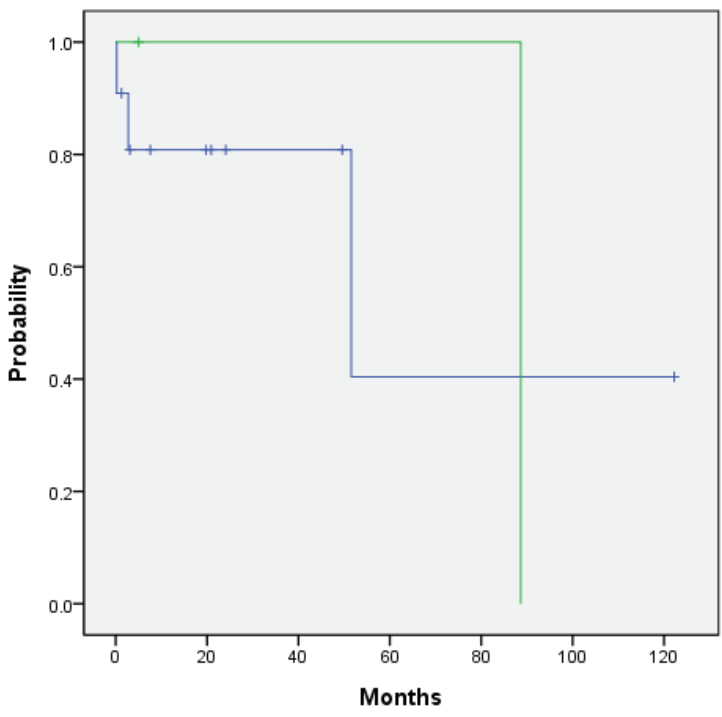

Figure 6b: Disease-free Survival $(n=13)$

NO HDR Boost $=5$ yr survival $47 \%$,

median survival 59.0 months YES HDR Boost = 5 yr survival $100 \%$, median survival 90.0 months $\mathrm{P}$-Value $=0.52$

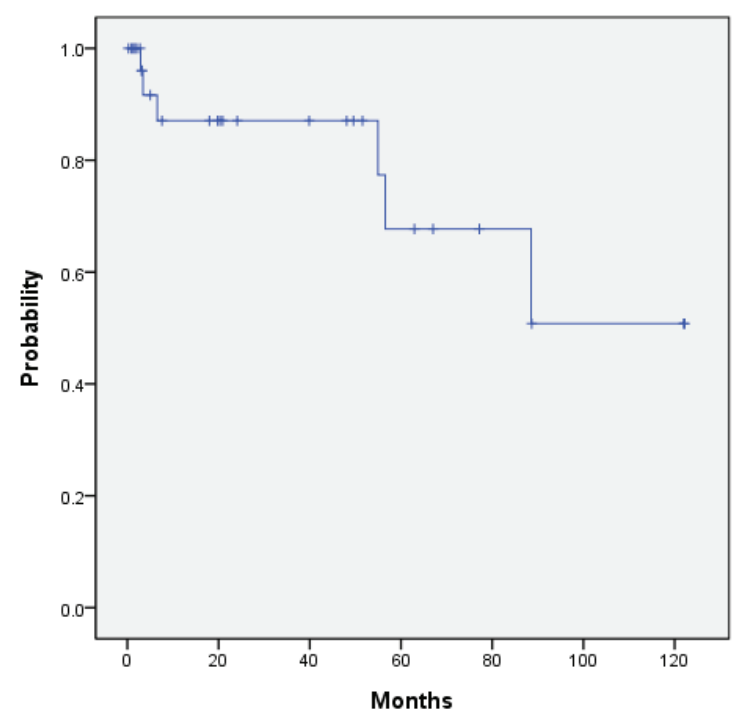

Figure 7a: Locoregional Control $(\mathrm{n}=33)$.

5 yr survival $72 \%$ and median survival has not yet been reached.

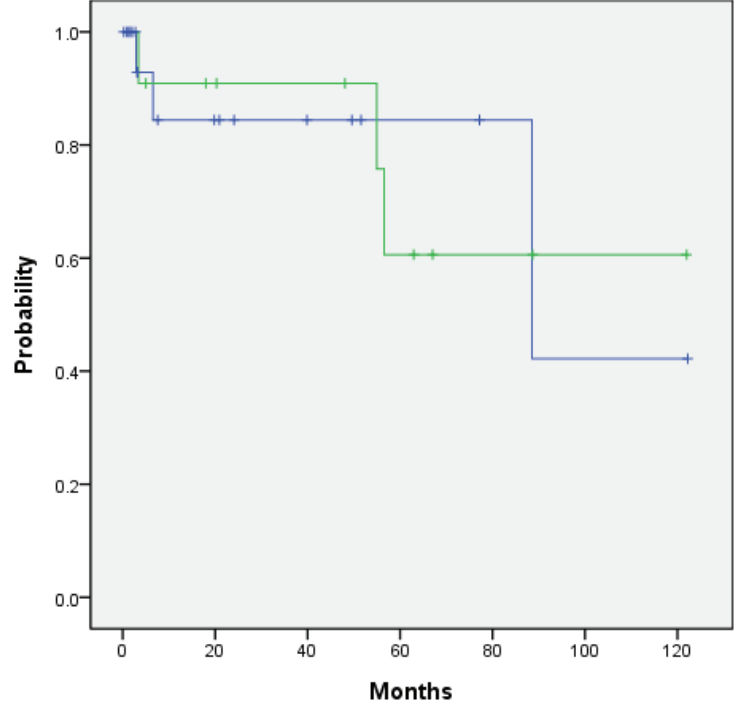

Figure 7b: Locoregional Control by HDR Boost $(n=23)$ (excluding tmt group 1$)$. NO HDR, 5 year survival $87 \%$

median survival time $=94.2$ months YES HDR, 5 year survival $63 \%$ median survival time $=$ not yet reached $P-V$ alue $=0.469$

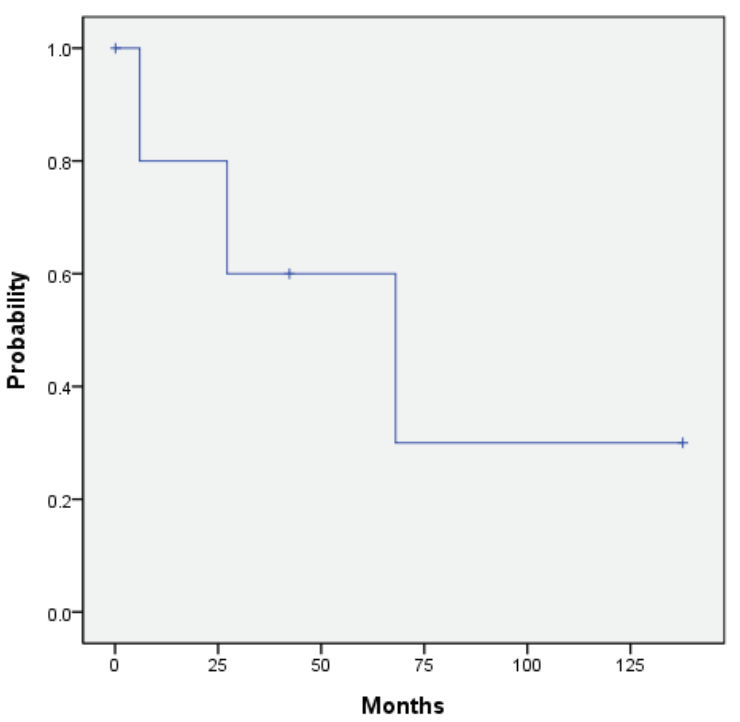

Figure 8: Overall survival of patients with local failure after salvage treatment $(n=6)$. Median Survival $=64.44$ months

5 yr survival $=61 \%$.

or increase in radiation dosage (Table 3). None of the patient who received radiation had greater than grade 3 toxicity.

\section{Discussion}

Primary tracheal tumors are exceedingly rare, and little information is available on efficacious treatments. Randomized trials do not exist for primary ACC of the trachea. Therefore we must rely on case reports and small retrospective studies to determine treatment options that will provide the greatest survival and quality of life for our patients. Historically surgery has been the preferred first line treatment of tracheal tumors, and although there is little data on the efficacy of neutron radiotherapy in treating ACC of the trachea, it is

Citation: Patel S, Chon CY, Tedrick L, Calvert JK, Lorimer D, et al. (2020) Efficacy of Neutron Radiotherapy for Primary Tracheal Adenoid Cystic Carcinoma: A Single Institution Retrospective Analysis. Glob J Cancer Ther 6(1): 015-022. DOl: https://dx.doi.org/10.17352/2581-5407.000030 
Table 3: Radiation related toxicity (RTOG)

\begin{tabular}{|c|c|c|c|c|}
\hline Patient & Treatment & Radiation & Dosage & Toxicity Grade \\
\hline 1 & XRT only & Neutron & 28.8 & 2 \\
\hline 2 & XRT only & Neutron & 19.2 & 1 \\
\hline 3 & XRT only & Neutron & 19.2 & 1 \\
\hline 4 & XRT only & Neutron & 18.4 & 2 \\
\hline 5 & XRT only & Neutron & 18.4 & 3 \\
\hline 6 & XRT + HDR & Neutron & 18.2 & 2 \\
\hline 7 & XRT + HDR & Neutron & 18.2 & 2 \\
\hline 8 & XRT + HDR & Neutron & 17.2 & 1 \\
\hline
\end{tabular}

believed to increase the overall five-year survival [17-19] . In this discussion, we address the trends observed from the data analysis of 33 patients with ACC in our study. This report updates our institutional experience with neutron radiotherapy as primary treatment for locally advanced ACC of the trachea and the efficacy of HDR endobronchial brachytherapy.

There is little data to support any single treatment modality for tracheal ACC. However, the largest published experiences are with surgical resection and thus surgery remains the standard treatment against which all other treatment modalities are compared [20-22]. While surgical resection has been the preferred method of curative treatment for ACC, it historically is only performed on less advanced tumors that tend to have an inherently better prognosis [23]. The classification of tumors as not surgically resectable is based on extensive regional disease or airway compromise [24]. Unfortunately, due to the invasive nature of ACC approximately $25 \%$ of all patients will present with locally advanced disease and are consequently ineligible for complete surgical resection In a recent study by Chen et al. that looked at the treatment modalities for 52 patients with ACC of the trachea, no significant disease free survival and overall survival were seen between patients with unresectable tumors who received radiation therapy alone versus those who received complete resection without adjuvant radiation therapy. Additionally, this study found improved disease free survival and overall survival in patients who received postoperative radiation therapy after incomplete resection [25].

Up until recently, photon radiotherapy has been the treatment of choice for these patients for whom surgery is not an option. However, previous studies have now shown a higher RBE of neutron radiotherapy on slowly progressing ACC tumors over photon radiotherapy [26]. Batterman, et al. reported a RBE of 8 for ACC as compared to 3-3.5 for normal late-reacting tissues. This demonstrates a therapeutic gain of 2.5 over conventional photon radiotherapy, and is thought to be the basis for the favorable results observed with neutrons in subsequent clinical trials. Conversely, in a study by Xie, et al. photon radiotherapy was suggested to be very effective. This study reported on 78 patients with primary tracheal neoplasms among which 12 were identified histologically as ACC. They reported a five-year overall survival rate of $90 \%$ for patients with ACC of the trachea treated with photon therapy postsurgical resection $(\mathrm{p}=0.255)$. The sample size in Xie's study is very small, as well as the fact that DFS is not reported and should therefore be interpreted with this in mind. It makes it difficult to compare to this dataset as ACC patients can live many years with disease.

This data supports the Bittner, et al. conclusion that neutron radiotherapy is an effective treatment for locally advanced tracheal ACC. The data demonstrates a survival benefit for patients with unresectable ACC tracheal tumors receiving neutron radiotherapy as a primary treatment with a five-year overall survival of $93 \%$ and a five-year disease-free survival of $38 \%$. In terms of disease-free survival, patients receiving surgery had improved five-year outcomes over those receiving neutron radiotherapy only. This is likely due to patients in the surgical treatment group having less advanced disease state at diagnosis.

These numbers are encouraging in the search for a definitive treatment for tracheal ACC. However, it is important to note that the data presented in this review is not statistically significant due to the small sample size. This mirrors the low incidence of tracheal ACC in the population.

Beginning in November 2000 HDR endobronchial brachytherapy was offered to eligible patients with ACC of the trachea in attempts to address suboptimal local control rates [27]. HDR endobronchial brachytherapy was chosen as an adjuvant therapy because it was believed to be the safest and most direct way of increasing the dose at the site of the tumor while avoiding late tissue toxicity. HDR was performed on eleven ACC patients in our cohort. Consistent with Bittner, et al., our data analysis did not detect a statistically significant difference between patients who did and did not receive HDR endobronchial brachytherapy in locoregional control (63\% vs. $87 \%, p=0.469$ ), five-year disease-free survival ( $46 \%$ vs. $44 \%$, $\mathrm{p}=0.251$ ) or five-year overall survival ( $89 \%$ vs. $72 \%, \mathrm{p}=0.489$ ).

\section{Conclusion}

In our cohort the failure sites were evenly distributed between local and distant, highlighting the need for both better local and systemic therapies. Local control continues to be a challenge, but data with respect to primary neutron radiotherapy and HDR endobronchial brachytherapy are certainly encouraging, especially when considering a patient population with locally advanced disease. The data supports the conclusion that ACC of the trachea can be treated with a combination of neutron radiation and HDR boost with favorable outcomes.

\section{References}

1. Maziak DE, Todd TR, Keshavjee SH, Winton TL, Van Nostrand P, et al. (1996) Adenoid cystic carcinoma of the airway: thirty-two-year experience. J Thorac Cardiovasc Surg 112: 1522-1531. Link: https://bit.ly/2Zmz183

2. Urdaneta Al, Yu JB, Wilson LD, et al. (2011) Population based cancer registry analysis of primary tracheal carcinoma. Am J Clin Oncol 34: 32-37. Link: https://bit.ly/3cWIWFC

3. Azar T, Abdul-Karim FW, Tucker HM (1998) Adenoid cystic carcinoma of the trachea. Laryngoscope 108: 1297-1300. Link: https://bit.ly/2zkWP1s

4. Prommegger R, Salzer GM (1998) Long-term results of surgery for adenoid cystic carcinoma of the trachea and bronchi. Eur J Surg Oncol 24: 440-444. Link: https://bit.ly/2zkWXxY 
5. Bittner N, Koh JW, Laramore GE, Patel S, Mulligan SM, et al. (2008) Treatment of locally advanced adenoid cystic carcinoma of the trachea with neutron radiotherapy. Int J Radiat Oncol Biol Phys 72: 410-414. Link: https://bit.ly/3g977T5

6. Garden AS, Weber RS, Morrison WH, Ang KK, Peters LJ (1995) The influence of positive margins and nerve invasion in adenoid cystic carcinoma of the head and neck treated with surgery and radiation. Int J Radiat Oncol Biol Phys 32 619-626. Link: https://bit.ly/3bRKgYX

7. Bittner N, Koh JW, Laramore GE, Patel S, Mulligan SM, et al. (2008) Treatment of locally advanced adenoid cystic carcinoma of the trachea with neutron radiotherapy. Int J Radiat Oncol Biol Phys 72: 410-414. Link: https://bit.ly/3g977T5

8. Xie L, Fan M, Sheets NC, Chen RC, Jiang GL, et al. (2012) The use of radiation therapy appears to improve outcome in patients with malignant primary tracheal tumors: a SEER-based analysis. Int J Radiat Oncol Biol Phys 84: 464470. Link: https://bit.ly/3ec1dPr

9. Battermann JJ, Breur K, Hart GA, van Peperzeel HA (1981) Observations on pulmonary metastases in patients after single doses and multiple fractions of fast neutrons and cobalt-60 gamma rays. Eur J Cancer 17: 539-548. Link: https://bit.ly/3bRL1kL

10. Douglas JG, Laramore GE, Austin-Seymour M, Koh WJ, Lindsley KL, et al. (1996) Neutron radiotherapy for adenoid cystic carcinoma of minor salivary glands. Int J Radiat Oncol Biol Phys 36: 87-93. Link: https://bit.ly/36hr8SU

11. Douglas JG, Laramore GE, Austin-Seymour M, Koh WJ, Griffin TW (2000) Treatment of locally advanced adenoid cystic carcinoma of the head and neck with neutron radiotherapy. Int J Radiat Oncol Biol Phys 46: 551-557. Link: https://bit.ly/3cLSUJH

12. Bittner N, Koh WJ, Laramore GE, Patel S, Mulliganet MS, et al. (2008) Treatment of locally advanced adenoid cystic carcinoma of the trachea with neutron radiotherapy. Int J Radiat Oncol Biol Phys 72: 410-414. Link: https://bit.ly/3g977T5

13. Prommegger R, Salzer GM (1998) Long-term results of surgery for adenoid cystic carcinoma of the trachea and bronchi. Eur J Surg Oncol 24: 440-444 Link: https://bit.ly/2zkWXxY

14. Maziak DE, Todd TR, Keshavjee SH, Winton TL, Van Nostrand P, et al. (1996) Adenoid cystic carcinoma of the airway: thirty-two-year experience. J Thorac Cardiovasc Surg 112: 1522-1531. Link: https://bit.ly/2Zmz183

15. Douglas JG, Laramore GE, Austin-Seymour M, Koh WJ, Griffin TW (2000) Treatment of locally advanced adenoid cystic carcinoma of the head and neck with neutron radiotherapy. Int J Radiat Oncol Biol Phys 46: 551-557. Link: https://bit.ly/3cLSUJH

16. Battermann JJ, Breur K, Hart GA, van Peperzeel HA (1981) Observations on pulmonary metastases in patients after single doses and multiple fractions of fast neutrons and cobalt-60 gamma rays. Eur J Cancer 17: 539-548. Link: https://bit.ly/3bRL1kL

17. Battermann JJ, Breur K, Hart GA, van Peperzeel HA (1981) Observations on pulmonary metastases in patients after single doses and multiple fractions of fast neutrons and cobalt-60 gamma rays. Eur $\mathrm{J}$ Cancer 17: 539-548. Link: https://bit.ly/3bRL1kL

18. Douglas JG, Laramore GE, Austin-Seymour M, Koh WJ, Griffin TW (2000) Treatment of locally advanced adenoid cystic carcinoma of the head and neck with neutron radiotherapy. Int J Radiat Oncol Biol Phys 46: 551-557. Link: https://bit.ly/3cLSUJH

19. Xie L, Fan M, Sheets NC, Chen RC, Jiang GL, et al. (2012) The use of radiation therapy appears to improve outcome in patients with malignant primary tracheal tumors: a SEER-based analysis. Int J Radiat Oncol Biol Phys 84: 464 470. Link: https://bit.ly/3ec1dPr

20. Gaissert HA, Grillo HC, Shadmehr BM, Wright CD, Gokhale M, et al. (2004) Long-term survival after resection of primary adenoid cystic and squamous cell carcinoma of the trachea and carina. Ann Thorac Surg 78: 1889-1896. Link: https://bit.ly/3gbkKBi

21. Gaissert HA, Mark EJ (2006) Tracheobronchial gland tumors. Cancer Control 13: 286-294. Link: https://bit.ly/3gbAsMP

22. Webb BD, Walsh GL, Roberts DB, Sturgis EM (2006) Primary tracheal malignant neoplasms: the University of Texas MD Anderson Cancer Center experience. J Am Coll Surg 202: 237-246. Link: https://bit.ly/2TmwqqY

23. Bhattacharyya N (2004) Contemporary staging and prognosis for primary tracheal malignancies: a population-based analysis. Otolaryngol Head Neck Surg 131: 639-642. Link: https://bit.ly/2WPc0ZX

24. Bittner, N., et al. (2008). Treatment of locally advanced adenoid cystic carcinoma of the trachea with neutron radiotherapy. Int $\mathrm{J}$ Radiat Oncol Biol Phys 72(2): 410-414.

25. Chen, F., et al. (2014) Primary tracheal adenoid cystic carcinoma: adjuvant treatment outcome. Int J Clin Oncol. [Epub ahead of print]

26. Battermann JJ, Breur K, Hart GA, van Peperzeel HA (1981) Observations on pulmonary metastases in patients after single doses and multiple fractions of fast neutrons and cobalt-60 gamma rays. Eur J Cancer 17: 539-548. Link: https://bit.ly/3bRL1kL

27. Bittner N, Koh JW, Laramore GE, Patel S, Mulligan SM, et al. (2008) Treatment of locally advanced adenoid cystic carcinoma of the trachea with neutron radiotherapy. Int J Radiat Oncol Biol Phys 72: 410-414. Link: https://bit.ly/3g977T5

\section{Discover a bigger Impact and Visibility of your article publication with}

\section{Peertechz Publications}

\section{Highlights}

* Signatory publisher of ORCID

* Signatory Publisher of DORA (San Francisco Declaration on Research Assessment)

* Articles archived in worlds' renowned service providers such as Portico, CNKI, AGRIS, TDNet, Base (Bielefeld University Library), CrossRef, Scilit, J-Gate etc.

* Journals indexed in ICMJE, SHERPA/ROMEO, Google Scholar etc.

* OAI-PMH (Open Archives Initiative Protocol for Metadata Harvesting)

- Dedicated Editorial Board for every journa

* Accurate and rapid peer-review process

- Increased citations of published articles through promotions

* Reduced timeline for article publication

Submit your articles and experience a new surge in publication services (https://www.peertechz.com/submission).

Peertechz journals wishes everlasting success in your every endeavours.

Copyright: @ 2020 Patel S, et al. This is an open-access article distributed under the terms of the Creative Commons Attribution License, which permits unrestricted use distribution, and reproduction in any medium, provided the original author and source are credited.

Citation: Patel S, Chon CY, Tedrick L, Calvert JK, Lorimer D, et al. (2020) Efficacy of Neutron Radiotherapy for Primary Tracheal Adenoid Cystic Carcinoma: A Single Institution Retrospective Analysis. Glob J Cancer Ther 6(1): 015-022. DOI: https://dx.doi.org/10.17352/2581-5407.000030 